\title{
CRISE NO SISTEMA AGROALIMENTAR BRASILEIRO E COVID-19: UMA CHAMADA PARA UM ESTILO DE VIDA SUSTENTÁVEL
}

Ana Christina Duarte Pires

Setor Litoral da Universidade Federal do Paraná (SL/UFPR)

Matinhos - PR - Brasil

E-mail: anachrisdp@gmail.com

Orcid: 000.0003.3542.9926

\section{Maria Tarcisa Silva Bega}

Universidade Federal do Paraná (UFPR)

Curitiba - PR - Brasil

E-mail: tarcisa.silva@gmail.com

Orcid: https://orcid.org/0000-0003-4330-8454

Recebido em 24/05/2021. Aprovado em 22/07/2021.

DOI: http://dx.doi.org/10.5380/guaju.v7i2.81150

\section{Resumo}

O presente ensaio tem por objetivo relacionar as diversas crises provocadas pela pandemia de Covid-19 com o sistema agroalimentar capitalista neoliberal atual. A metodologia utilizada é uma revisão de literatura que parte de descrição de um cenário de degradação ambiental, causado pela agricultura realizada de forma exploratória em grande escala, às custas dos recursos naturais, com prejuízo à saúde das pessoas e sua relação com a obtenção do lucro. Iniciando com questionamentos sobre as diversas crises agravadas por esse sistema, é realizada uma discussão sobre um sistema alternativo de estilos de vida e de produção e consumo de alimentos que preserve todos os seres vivos, através de ações possíveis compartilhadas entre o meio rural e o meio urbano. Conclui-se esse texto com um convite a uma transformação de estilo de vida, por alternativas viáveis e reais, com diversos graus de comprometimento, a fim de evitar novas pandemias ou reduzir os seus impactos no meio ambiente, considerando sempre o ser humano como parte dele.

Palavras-chave: Covid-19. Sistema agroalimentar. Sustentabilidade. Estilo de vida. 


\title{
The brazilian agrifood system crisis and Covid-19: a call for a sustainable lifestyle
}

\begin{abstract}
This essay aims to relate the various crises caused by the Covid-19 pandemic to the current neoliberal capitalist agrifood system. The methodology used is a literature review that departs from the description of a scenario of environmental degradation, caused by the large-scale exploratory agriculture at the expense of natural resources, with harm to the people's health and its relation to profit. Starting with questions about the various crises aggravated by this system, a discussion is held about an alternative systems of lifestyles, food production and consumption that preserves all living beings, through possible actions shared between the rural and the urban environments. We conclude this text with an invitation to a lifestyle transformation, through viable and real alternatives, with various degrees of commitment, in order to avoid new pandemics or reduce their impacts on the environment, always considering the human being as part of it.

Keywords: Covid-19. Agri-food system. Sustainability. Lifestyle.
\end{abstract}




\section{Introdução}

O presente ensaio é uma reflexão sobre a pandemia de Covid 19 por meio da articulação entre as dimensões da sustentabilidade, entendidas por Caporal e Costabeber (2002) como social, ecológica, econômica, política, cultura e ética, realizada por meio de uma revisão de literatura. Sem nenhuma pretensão de soluções, estamos sob impacto de discussões já assentadas, realizadas pelo entrelaçamento dos temas Agroecologia e Sociologia com as primeiras reflexões sobre a pandemia por autores dessas áreas. O que se observa é um movimento que coloca em xeque a ordem neoliberal que domina o mundo, a hegemonia das grandes potências econômicas mundiais, os acordos que permitiram a construção de comunidades econômicas e a possibilidade de trazer ao centro dos debates uma forma de vida, talvez mais simples e com maior sustentabilidade ambiental, por meio do estilo de vida agroecológico. É nesse campo, de poucas certezas e muitas esperanças, que produzimos este texto.

Segundo Bosquerolli et al. (2020), Schneider et al. (2020) e Silva, Santos e Soares (2020), a Covid-19 vem sendo apontada como a causa da derrocada econômica de muitos países em desenvolvimento e subdesenvolvidos. Os autores relatam que mesmo nos países integrantes do G7, as medidas de isolamento dos contaminados e distanciamento social para toda a população, ao frearem radicalmente as oportunidades usuais de comércio e serviços, ou seja, presenciais, tiveram por consequência a elevação da taxa de desemprego e da porcentagem de população abaixo da linha de pobreza. Após a flexibilização dessas medidas, a retomada tem sido lenta a ponto de não conseguir reverter as consequências econômicas desse período de suspensão de atividades. Assim, a pandemia tem gerado uma crise econômica sem precedentes, num curto espaço de tempo e de forma global. Isso pode ser observado no caso do Brasil, onde expressões populares como "o Coronavírus vai acabar com o país" são usadas frequentemente pelos integrantes do governo que veem a pauta neoliberal em xeque, por representantes de grandes empresas que estão preocupados com suas taxas de lucro e se dissemina junto à população em geral, que repete tais discursos têm como caixa de ressonância a grande mídia. Ou seja, se torna dominante até mesmo entre os trabalhadores (BOSQUEROLLI et al., 2020; SANTOS, 2020).

No entanto, um olhar mais profundo sobre a pandemia de Covid-19 expõe outras crises, provocadas pelo sistema capitalista neoliberal que domina o mundo. Além das evidentes crises da economia e de saúde, a crise ambiental e a crise alimentar, como dimensões interdependentes que fazem parte de um sistema global, conforme descrevem 
Caporal e Costabeber (2002), foram expostas pela pandemia (MORIN, 2020). Santos (2020) explica essa associação de crises com a concentração de riqueza proporcionada pelo capitalismo e suas consequências: a extrema desigualdade social e a destruição da vida do planeta, prenúncio de uma catástrofe ecológica.

A relação da pandemia de Covid-19 com essa dinâmica pode ser compreendida através de uma análise dos rumos que tomou a agricultura a partir dos processos modernizadores nos países considerados agrícolas, a partir de década de 1960. Segundo Ploeg (2006, p. 13) "[...] o modo de produção empresarial pôde apenas se materializar e se desenvolver devido às novas condições introduzidas e consolidadas pelo projeto de modernização massiva iniciado nas décadas de 60 e 70". Com a sua expansão, tem sido crescente a verificação de danos ambientais causados pela agricultura modernizada que acabam se refletindo no comprometimento da saúde humana, através de intoxicações pela contaminação por agrotóxicos, poluição do ar e da água e por uma alimentação de quantidade e qualidade nutricional deficiente (AUGUSTO et al., 2012). Parte-se, portanto, do pressuposto de que a pandemia não é causa do desmoronamento de países: é consequência das formas pelas quais esses países têm sido submetidos às normas da economia mundial. Ou seja, é a efetivação do que tem sido previsto pelos estudos ambientalistas em várias áreas: a insustentabilidade da produção e do consumo de bens, serviços e produtos.

Portanto, diante desse quadro, o objetivo do presente texto é relacionar as diversas crises provocadas pela pandemia de Covid-19 com o sistema agroalimentar capitalista neoliberal atual, apresentando um sistema sustentável e alternativo a fim de evitar o aparecimento de novas pandemias e outras catástrofes.

Após essa Introdução, na seção 2 é descrita a trajetória do sistema agroalimentar global, que deixou o objetivo de sanar a fome mundial e passou a ter como meta a obtenção e acumulação de lucro por grandes conglomerados econômicos. São apresentadas as condições em que esse processo ocorreu e que determinam a sua continuidade. São relacionados os impactos dessa dominação sobre o meio ambiente e sobre a saúde humana, de forma a proporcionar o entendimento de como esse sistema se tornou insustentável, ao mesmo tempo em que chama para a necessidade da adoção de outros estilos de vida, compatíveis com a sustentabilidade, em suas variadas dimensões.

Na seção 3, é demonstrado de que forma um outro estilo de vida, inspirado na agroecologia, caracterizado por outras formas de produzir e consumir alimentos, é uma ferramenta necessária para a retomada da sustentabilidade. Aborda o entendimento da 
conscientização sobre a necessidade de ressignificar o meio ambiente e relações sociais, como chave para transformação de práticas e hábitos de consumo e de produção, a fim de proporcionar uma maior independência dos sistemas de mercado que fazem parte do sistema convencional de produção. É apresentada a base dessa transformação como a busca da relação harmoniosa entre indivíduo, sociedade e natureza, que pode envolver vários sujeitos e vários locais, entendendo a importância de ações individuais e ações coletivas na adoção de estilos de vida sustentáveis, em vários graus de envolvimento.

Apontando para um fechamento do texto, na seção 4, é efetivada a chamada para um outro estilo de vida após a pandemia. São apresentadas as condições que tornam a proposta de um estilo de vida sustentável, demonstrando as diversas ações necessárias para a manter a sua viabilidade e assegurar sua estabilidade pelos próximos tempos. São consideradas, nessas condições, que essa outra forma de ver o mundo envolve, necessariamente, um repensar da sociedade e da ciência. É considerada a importância da valorização da agricultura familiar como forma principal do provimento de alimentos frescos, a preço justo, a todos os segmentos da sociedade e o quanto a mobilização social é decisiva para que esses objetivos sejam alcançados.

Por fim, na última seção, são apresentadas algumas breves conclusões.

\section{Impactos globais do sistema agroalimentar dominante sobre o meio ambiente e a alimentação}

Com a justificativa de aumentar a produção de alimentos para sanar a fome mundial, a agricultura em larga escala e para a exportação tem causado severos impactos no meio ambiente e nas sociedades (OCTAVIANO, 2010). Além disso, segundo FAO (2018), o número de pessoas passando fome no mundo só tem subido: passou de 815 milhões de indivíduos, em 2016, para quase 821 milhões em 2017. Por essa razão, não se pode justificar esse tipo de agricultura como necessário para aumentar a produção de comida. O objetivo real é o lucro e a acumulação de capital por poucos conglomerados econômicos multinacionais que dominam o ciclo de mercado, obtidos desde a venda de insumos e equipamentos até os produtos finais (PLOEG, 2008).

São esses grandes conglomerados econômicos que determinam desde as condições de produção até o tipo de consumo, a fim de que se dê prioridade a produtos industrializados e processados pelas indústrias pertencentes aos seus próprios grupos (BORSATTO, 2011). Harvey (2020) descreve esse mecanismo como uma espiral de infinita 
expansão e crescimento. Como o seu interesse é exclusivamente econômico, a qualidade dos alimentos fica para segundo plano: o que chega à mesa dos consumidores são alimentos de baixa qualidade nutricional, com resíduos dos agrotóxicos e fertilizantes usados na agricultura de larga escala (AUGUSTO et al., 2012).

Para entender como ocorre a interferência das empresas agroalimentares capitalistas no setor de produção de alimentos, parte-se do princípio de que a agricultura é uma atividade que envolve, obrigatoriamente, a necessidade de espaço (terra) para o cultivo de alimentos, sejam eles de origem vegetal ou animal. Mas, fatalmente, esta forma de produzir encontrou limites geográficos, ou seja, de área livre para plantio. Esse fato pode ser entendido em Harvey (2005), o qual observa que as formas originais de acumulação capitalista foram até seus limites físicos, seja por não haver mais espaço disponível ou pelo fato de que as terras aptas existentes pertencem a pessoas físicas que já detinham a posse legal da terra. É o caso do Brasil, onde, segundo IBGE (2018), 72\% dos estabelecimentos rurais pertence a produtores individuais na forma de pessoa física, o que equivale a $70 \%$ da área rural total. Como para o capital é necessário constante expansão da produção como garantia da acumulação e do lucro, soluções foram encontradas na forma de domínio da tecnologia que permite a exploração intensiva da terra (HARVEY, 2005).

Uma delas compreende a expansão forçada da agricultura para áreas sem tanta aptidão agrícola e para as ocupadas, originalmente, por florestas (PIGNATTI; MACHADO, 2011). Para se ter ideia de o quanto essa atividade representa na substituição de áreas naturais por áreas agrícolas, segundo IBGE (2018), apenas 29\% da área rural é ocupada por matas e florestas. Do restante da área transformada, $45 \%$ é ocupada por pastagens e $18 \%$ por lavouras, ficando 8\% para outros tipos de ocupação. Dados do Instituto Nacional de Pesquisas Espaciais (INPE, 2020), mostram que o desmatamento aumentou em 30\% de 2018 a 2019'. Os impactos dessas queimadas, além da perda da biodiversidade apontada no início deste texto, agudizam os casos de internações hospitalares, pressionando o sistema público de saúde, pelo risco de intoxicação da população local pela fumaça (RIBEIRO; ASSUNÇÃO, 2002).

A biodiversidade local é um agente estabilizador das relações e dimensões de seu ecossistema. Quando essa biodiversidade é destruída, ocorre um desequilíbrio nesse ecossistema, que até então mantinha estáveis as relações entre seus integrantes, inclusive

1 Como ferramenta de desmatamento, segundo o INPE (2020), os registros de focos de incêndio de janeiro a agosto de 2019 são os maiores em 7 anos, com aumento de $82 \%$ em relação ao mesmo período de 2018. Destes focos, 52,5\% concentram-se na Amazônia, 30\% estão no Cerrado e 10\% na Mata Atlântica, acompanhando a expansão geográfica das atividades agrícolas em larga escala. 
com elementos nocivos aos seres humanos, chamados patógenos. Em uma situação de desequilíbrio, suas populações proliferam sem controle, em busca de mais fontes de energia para garantir a sua sobrevivência. E o encontro direto de formas de patógenos altamente reprodutivas - como muitos vírus e bactérias - com hospedeiros cujo sistema imunológico ainda é ineficiente para combatê-los, estabelece uma situação ideal e favorável para o contágio e o desenvolvimento de infecções. Segundo Schneider e Oliveira (2020, p. 93):

\footnotetext{
Os animais silvestres, principalmente morcegos, roedores e primatas não humanos, são reservatórios de muitos vírus e outros agentes infecciosos; se estressamos seus ambientes, aumentamos as chances de que desenvolvam a doença, expilam o vírus no ambiente e o transmitam para outros animais e o homem.
}

Dessa forma, seres humanos e animais domesticados para uso econômico e recreativo, ao serem inseridos em locais antes ocupados por florestas e outras vegetações naturais, tornam-se hospedeiros e vetores dos patógenos que se encontravam em seu ambiente natural. Essa relação, inclusive, pode ser notada pela atribuição de nome a outras epidemias da atualidade, como a gripe suína e a gripe aviária. E, além disso, a migração forçada ou a captura de espécies silvestres para centros urbanos, por ter seu habitat natural destruído, também pode se constituir em um vetor, por carregar consigo formas ativas e inativas dos patógenos (SCHNEIDER; OLIVEIRA, 2020).

Além de oportunizar formas de contato com os patógenos, o atual sistema agroalimentar também pode comprometer outros aspectos que compõem a imunidade humana. Tanto no processo de produção como matéria prima, quanto no processo de transformação, a moldagem desse sistema pode ser relacionada à resistência a doenças através da qualidade da alimentação (PORTO; SOARES, 2012). Formas de disposição e de oferta do produto final, através de formas processadas, artificializadas e/ou congeladas, contribuem com a perda da sua qualidade nutricional (BARUTTI, 2013). Portanto, observa-se que essa base alimentícia desfavorece a formação do sistema imunológico de quem a consome.

A oferta de produtos frescos também é comprometida quando é intermediada pelas empresas agroalimentares. É um fato que também sinaliza a precariedade alimentar, não só em quantidade, mas em qualidade nutricional, fundamental quando se trata de resistência a doenças, manutenção e recuperação da saúde (SCHNEIDER et al., 2020). Para entender como ocorre esse processo de modificação, mesmo de alimentos frescos, Barutti (2013) considera que se alimentos com mais açúcar detém a preferência de consumo, a 
produção convencional produz vegetais com diluídas concentrações de vitaminas e seus sabores naturais. Em outras palavras, alardeado desde a Revolução Verde como a salvação para a fome, este sistema gera, de fato, maior adoecimento coletivo de pessoas e animais domésticos. É um mecanismo que produz lucro por ocasionar a doença e para curá-la, já que os conglomerados englobam tanto as empresas de alimentos quanto a de medicamentos.

Esse modelo, à base da exploração dos recursos naturais sem reposição, em que a produção de lucro é mais interessante que a produção de comida, devasta territórios, compromete a alimentação da população rural e urbana e expulsa do campo povos tradicionais do mundo inteiro, principalmente nos países aos quais é atribuída uma vocação agrícola, que é o caso da América Latina (PASMIÑO et al., 2017).

A relação dos agrossistemas com os aspectos econômicos condiciona a sua relação com o meio original. No caso dos agroecossistemas de agricultura convencional, onde o objetivo principal da produção é o lucro, o tipo de produção é determinado pelas demandas do mercado global e não com a conservação dos recursos naturais utilizados para a produção da matéria prima geradora desse lucro. A produção extrativa em larga escala destrói os agroecossistemas, reduz drasticamente a biodiversidade, provoca danos ambientais e expulsa do campo os produtores que não possuem condições de acompanhar os altos custos de produção. É um círculo vicioso que fortalece os detentores de capital e agrava as situações de exclusão social, por meio do crescimento da pobreza e do êxodo rural, o que provoca o agravamento de crises de origem social e ambiental. O comprometimento da agricultura exploratória nas causas dessas crises pode ser entendido em Andrade e Romeiro (2011, p. 2), os quais alertam que as análises ecossistêmicas globais:

\footnotetext{
[...] apontam para uma trajetória de degradação dos ecossistemas terrestres, reduzindo os benefícios derivados para o bem-estar humano e colocando em risco a própria sustentabilidade do sistema econômico e bem-estar das gerações futuras. A crescente perda de diversidade biológica, associada ao não reconhecimento das contribuições dos ecossistemas para as atividades humanas, são as principais causas desse estado.
}

Portanto, os danos ambientais e o comprometimento da segurança alimentar no Brasil e no mundo são reflexos do monopólio das grandes empresas sobre a produção e o consumo de alimentos, que tem por objetivo atender às demandas do sistema capitalista neoliberal (PLOEG, 2008; BORSATTO, 2011). Além de não chegarem à mesa da população 
em quantidade suficiente, esses alimentos são comprometidos nutricionalmente, o que caracteriza uma associação entre crise alimentar e crise ambiental, que resulta no agravamento da crise de saúde.

Não se trata, portanto, de se isolar uma pandemia, como a de Covid-19, apenas à dimensão de saúde. Segundo Morin (2020), a crise revelada é construída por fatores sociais, políticos, econômicos e ambientais. Nesse sentido, são os países com altos índices de vulnerabilidade ${ }^{2}$ social os mais expostos aos piores resultados da pandemia. Apesar de as menções populares afirmarem que o Coronavírus colocou toda a espécie humana em condições de igualdade, as reflexões apresentadas em Agamben et al. (2020) salientam que é no modelo regido pelo capitalismo onde as condições de exclusão social e econômica determinam a sua discriminação. Condições estas que Santos (2020) ressalta já existirem antes da pandemia, alertando para a necessidade de uma transformação.

Assim, a proposta de uma transformação nos estilos de vida pode atingir sujeitos, várias realidades e em diferentes graus de comprometimento (BRANDENBURG, 2010). A transformação parte de uma conscientização a respeito dos problemas sociais e ambientais ante os quadros de exploração comercial da natureza que são capazes de agravar os efeitos de uma pandemia (SILVA et al., 2020a). Essa conscientização leva a um despertar para estilos de vida que adotam relações de produção e consumo de alimentos de forma mais justa com o meio ambiente; para mudanças da relação ser humano e natureza, que podem transformar as relações sociais, melhorar a distribuição de renda e se constituírem como alternativas à dominação unilateral dos espaços e urbanização territorial (MORIN, 2020).

O acirramento dos conflitos socioambientais revelados pela Covid-19 é capaz de chamar para movimentos compostos por uma complexidade de outras dimensões (MORIN, 2020). Essas dimensões não restringem a vida a um modo nocivo de produção e consumo de exaltação ao mercado.Trata-se de uma forma que reconhece, valoriza e trazà tona, novamente, os saberes comprometidos com a preservação dos recursos naturais do planeta. Esse movimento provocado pelas tensões do mundo capitalista, dominado pela economia e tecnologia, atende aos impulsos por mudanças estruturais na sociedade (ELIAS,1994). A fim de fazer frente a essa dominação, a forma e a qualidade de comportamentos humanos estão sendo alterados, ocasionando uma busca coletiva por um estilo de vida que possibilite uma maior independência do mundo material e tecnológico, aproximação da natureza, de uma

2 Neste texto, o termo vulnerabilidade refere-se a condições de ausência ou precariedade no acesso à renda, a bens e a serviços públicos. 
cultura sustentada pelo compartilhamento e troca e por uma vida saudável garantida pela soberania alimentar como direito de todos os segmentos da sociedade (SINGER, 2002).

A proposta de relações alternativas de mercado e de processos de comercialização de produtos desenvolve-se com base nos princípios da Economia Solidária que, por definição, é um modo de produção que se caracteriza pela igualdade. Segundo Singer (2002 p. 16), “[...] o objetivo máximo dos sócios da empresa solidária é promover a economia solidária tanto para dar trabalho e renda a quem precisa como para difundir no país (ou no mundo) um modo democrático e igualitário de organizar atividades econômicas". A sua característica central é a posse e a gestão coletivas dos meios de produção realizada diretamente por quem com eles trabalha, de uma forma democrática. Ela basicamente demonstra que o trabalho pode ocorrer de forma diferente da empresa capitalista, uma vez que esta é cada vez mais excludente e injusta socialmente. Este modelo econômico demonstra que a gestão capitalista, além de não ser a única, não é indispensável. Originou-se na necessidade de formas alternativas para a manutenção da sobrevivência de grupos sociais excluídos e marginalizados pelo sistema convencional.

Por princípio, a Economia Solidária traduz os interesses e as necessidades de vários grupos, para sobreviverem e terem vida digna. E esse movimento compreende, além de quem dele precisa para sobreviver, também de grupos que tem como ideal escapar dos processos massificados, exploradores e controladores da vida, representados pelo modelo hegemônico (SINGER, 2002).

Os sujeitos, entre eles os do campo, encontram nesses movimentos uma forma de sustento e de promoção de autoestima, que lhes permite manterem-se economicamente sustentáveis, não sendo consumidos ou anulados. Por isso, cada vez mais empreendimentos de economia solidária vem ganhando espaço, formados por produtores e por consumidores ${ }^{3}$. Segundo Singer (2002 p. 95), “[...] essa outra modalidade de cooperativas de produção e de consumo que tem crescido acentuadamente é a nova onda de cooperativas de alimentos orgânicos e promotoras de tecnologias alternativas". Associadas a movimentos populares como as feiras para a comercialização, estas cooperativas resultam de um movimento de

\footnotetext{
3 A Economia Solidária é praticada no mundo inteiro, como uma nova forma de organização que atenda problemas sociais em nível local. Envolvem produtores, consumidores e opinião pública na mobilização por um sistema alternativo às regras e às práticas do comércio convencional e da assistência à população privilegiada. Em países da Europa como Dinamarca, Alemanha, Suécia, França e Reino Unido, associações que representam minorias culturais, como portadores de deficiência, mulheres e crianças tem se organizado na criação de mercados sem fins lucrativos e de instituições de acolhimento, visando o melhoramento das condições de vida e a proteção do ambiente.
} 
contracultura que visa preservar a natureza, eliminar a discriminação racial e sexual e, de modo geral, se opõem ao capitalismo, sobretudo em sua forma neoliberal. Dessa forma, esse comércio alternativo é capaz de oferecer resiliência às populações mais excluídas, como agricultores familiares, já que, segundo Schneider et al. (2020, p. 175), "produtores integrados em cadeias agroindustriais e aqueles conectados a cadeias curtas de abastecimento têm tido menores perdas de renda", inclusive durante a pandemia de Covid-19.

\section{Estilo(s) de vida sustentável}

Um estilo de vida ${ }^{4}$ sustentável pode abranger sujeitos tanto do meio rural quanto do meio urbano. Neste sentido, a inversão da ótica sobre as condições que definem e determinam a repetição contínua do estilo de vida hegemônico serve de base para a constituição desses outros sujeitos e, consequentemente, uma outra forma de se relacionar com a sociedade ao seu entorno, com o local e com a natureza. Portanto, primando pela sustentabilidade, a construção desse estilo de vida preconiza se desenvolver com menor impacto negativo possível a todos os componentes do meio ambiente (BRANDENBURG, 2010).

Não se trata de um retrocesso, mas sim de um movimento colaborativo. $\mathrm{Na}$ constituição do estilo de vida desses sujeitos, o moderno se alia ao tradicional, no momento em que é reconhecida a relação natural das sociedades com o meio, passando a inspirar as diretrizes para a retomada da relação harmoniosa entre todos os seres da natureza. Fazem parte das práticas desses sujeitos os fundamentos educacionais e científicos, as práticas solidárias e a democratização do saber. Como uma forma alternativa aos modelos sociais autoritários, excludentes e repressores, há a concepção de que as ações individuais assumem uma responsabilidade com o seu reflexo para a sociedade (BRANDENBURG, 2010).

No entendimento de um estilo de vida alternativo, o desenvolvimento individual reconhece o dos demais indivíduos ao seu entorno e na interação de todos eles como sociedade. É esse sistema, composto por diversos elementos, o estilo de vida alternativo, numa complexidade de diversos elementos, interagindo entre si, modificando-se e modificando o todo, sendo sujeito e objeto no mesmo sistema (MORIN, 2001).

4 Estilo de vida, neste trabalho, refere-se a maneira de viver, de se comportar, agir e pensar das pessoas, assim como a sua postura perante a vida. 
Esse compromisso envolve pensar e agir local e globalmente, de forma a apoiar a constituição de formas de organização social, de fazer política e de construir economias, instituições, estruturas, relações e espaços educadores alternativos ao modelo hegemônico. Assim, a transformação parte do autoconhecimento para o reconhecimento de grupo e da coletividade, na forma de cooperação e colaboração. Nesse universo existe uma ordem social que possibilita a harmonização entre o desenvolvimento pessoal de cada indivíduo e, por outro lado, um trabalho coletivo de muitos no tocante à manutenção do social como um todo. Elias (1994, p. 16) já nos ensinava que não há um abismo que separa o individual do social, pois, “[...] ninguém duvida de que os indivíduos formam a sociedade ou de que toda sociedade é uma sociedade de indivíduos". Dessa forma, no entendimento de um estilo de vida alternativo, o desenvolvimento de pessoas e sociedade ocorre em um formato de rede ${ }^{5}$.

A necessidade de mudança é despertada quando se toma consciência de que os interesses dominantes se revelam incompatíveis com um estilo de vida sustentável. Orepensar sobre suas relações entre si e com o meio gera outras visões de mundo, as quais contribuem para a construção deste mundo. E o modo de viver alternativo despertado por esse repensar constrói, através da identificação de valores comuns entre os sujeitos, a sua estrutura com um grupo social, mesmo heterogêneo, cujo comprometimento é a transformação para uma sociedade sustentável. Portanto, os sujeitos desse movimento também são diversos: podem partir de meios sociais onde uma vida alternativa já era incorporada nos seus hábitos ou podem partir de uma transformação através de uma conscientização feita ao longo do caminho, determinada pelas instituições por onde os indivíduos passam. Trata-se, portanto, de uma diversidade de outros sujeitos que possuem, em comum, a busca pelo bem viver, para si, para os outros seres e em harmonia com natureza. Independente do grau de comprometimento, Obregón (2013) identifica traços comuns que definem o objetivo coletivo de transformar hábitos, pensamentos e ações a fim de um bem viver:

a) igualdade social de indivíduos heterogêneos e diversos, contra a classificação desigual e a identificação racial/sexual/social da população mundial. Consequentemente, essas diferenças não seriam mais a fonte ou o argumento da desigualdade social dos indivíduos;

b) agrupamentos, pertences e/ou identidades como produto das decisões livres e autônomas de indivíduos livres e autônomos;

5 Para Elias (1994), a sociedade configura-se na forma de uma rede, composta de interações entre os diversos indivíduos que compõem:o"eu"e o"tu",o“nós"e o"eles", iguais ou não, entre constante dinâmica de interdependência. 
c) reciprocidade entre grupos e/ou indivíduos socialmente iguais, na organização do trabalho e na distribuição dos produtos;

d) redistribuição igualitária dos recursos e produtos, tangíveis e intangíveis, do mundo, entre a população mundial;

e) tendência de associação coletiva, em escala local, regional ou global, com o modo de produção e gestão diretas, como mecanismo eficaz de distribuição e redistribuição de direitos, obrigações, responsabilidades, recursos, produtos, entre os grupos e seus indivíduos.

O ponto de partida da transformação para modos de vida alternativos com base no bem viver é o questionamento profundo das necessidades materiais e simbólicas vendidas pelo modelo hegemônico, como, por exemplo, o desejo de consumo, originado no apelo midiático como se fosse uma obrigação, um sinal de poder. É isso que orienta e organiza tais práticas através de um ciclo retroalimentado e mantido pelo mercado convencional, vinculando a posse dos seus produtos a uma almejada posição social (BOURDIEU, 1979).

Por outro lado, Madeira et al. (2018) reconhecem que o estilo de vida atual é resultado das influências geradas por esse apelo na consciência coletiva. Segundo as mesmas autoras, informações, pressão dos pares e padrões culturais são capazes de ligar cada indivíduo com o meio, inclusive considerando seus conflitos. Assim, um estilo de vida consumista pode, também, produzir questionamentos no momento em que passa a ser identificado com processos de importância coletiva como exclusão social e danos ao meio ambiente. Tais questionamentos levam a uma avaliação sobre a necessidade real dos produtos e a maneira de apropriação6 desses produtos e/ou bens, sob a ótica dos impactos desse consumo sobre o meio e sobre a sociedade. São valores e saberes éticos que orientam os modos alternativos de vida através de outros modos de produção, de relações sociais e de consumo (MORAES et al., 2017).

No que cabe à população urbana, como consumidora, o movimento de consumo alternativo vem crescendo. São os produtos orgânicos e agroecológicos, disponíveis para quem possui poder aquisitivo compatível, ou seja, para quem pode escolher o que consumir: a entrega de cestas de produtos vindos da agricultura familiar aumentou seu campo de ação como um dos desdobramentos da pandemia. Na proibição de espaços abertos de comércio, como as feiras e eventos sociais, os produtores familiares foram suprimidos de sua fonte

6 As formas de apropriação de produtos e bens, neste trabalho, referem-se ao questionamento sobre a propriedade dos bens ou produtos, ou seja, se eles podem ser socializados ou são necessariamente de uma posse privada. 
de sustento. Por iniciativas individuais ou de cooperativas de produtores e consumidores, a alternativa de entrega dos produtos diretamente ao consumidor tem garantido a continuidade de sua renda (SCHNEIDER et al., 2020).

Ao promover a comercialização direta, a entrega de produtos do produtor ao consumidor evita a especulação financeira dos atravessadores, quebra a hegemonia dos grandes mercados e consome menos combustível, já que as entregas atendem as regiões próximas das propriedades rurais.

Da parte do consumidor, o recebimento de produtos em sua residência, além de evitar a sua exposição ao contágio pelo vírus, ainda fornece alimentos mais limpos e de alta qualidade nutricional e é capaz de provocar um repensar sobre sua origem, ou seja, de onde vem e como é produzido (SCHNEIDER et al., 2020). A pandemia, inclusive, impactou diretamente nesse tipo de consumo, pois tem sido constante a procura por alimentos saudáveis - como reforço da imunidade -, e entregues em domicílio, diminuindo as possibilidades de contato com o Coronavírus. Segundo Schneider et al. (2020 p. 179):

\begin{abstract}
Há duas questões ligadas às novas dinâmicas de consumo alimentar geradas pelo aumento do tempo das pessoas em suas casas e que têm impactado diretamente nas compras virtuais da agricultura familiar: o primeiro referese à possibilidade de cocção dos alimentos, gerando aumento da procura por produtos menos processados e frescos; o segundo fator diz respeito a questões de praticidade e conveniência, que reforçam escolhas por entregas de alimentos em casa, levando os consumidores a optarem por trabalhadores inseridos nesses sistemas.
\end{abstract}

Observa-se, assim, uma relação de dependência cooperativa, pois o produtor rural tem destino certo para a sua produção e o consumidor urbano que, além do ganho em alimentos saudáveis, ainda estimula o sustento daquele produtor. Novos espaços são construídos com esse intercâmbio e são vantajosos tanto para o produtor rural quanto para o consumidor. Portanto, a necessidade de mudança de hábitos de consumo de alimentos demonstra que esse movimento alternativo cooperativo de produção-venda-compraconsumo deixou de ser uma utopia e passou a ser um movimento real e praticável (SINGER, 2002). Além disso, laços de solidariedade e de conscientização que envolvem a alimentação foram reforçados, pois, na entrega direta, a comida passa assumir uma face, construída por meio do contato direto do produtor com o consumidor: o rosto de quem produz aparece fisicamente para quem consome e vice-versa. Tal interação é eliminada se realizada por mediação de mercados e os integrantes que fazem parte dessa rede, isolados. 
Essa aproximação e racionalidade, através do reconhecimento de produtores e consumidores como pessoas e as suas relações como sociedade são elementos chave para o reconhecimento das relações entre campo e cidade, conforme Brandenburg (2010, p. 426) que vê essa interação como:

\begin{abstract}
O rural ecologizado é um projeto advindo do cotidiano, do mundo da vida dos agricultores e de agentes de desenvolvimento com essa visão de mundo, porque traz na matriz uma reação à dominação exclusiva da racionalidade instrumental do projeto modernizador excludente. A essa reação associa-se uma demanda crescente da população urbana por um consumo do verde, de tradições e de uma atitude de precaução ao risco.
\end{abstract}

Assim, na busca por uma sociedade sustentável em suas diversas dimensões, a aproximação entre campo e cidade podem levar as sociedades a internalizarem outros valores sobre bases de sustentabilidade ecológica e equidade social. Portanto, novas abordagens, ou ressignificação das já existentes, resultam em um processo de reconstrução de sociedades que desenvolvem hábitos que fazem parte de um outro estilo de vida que não corresponde e, muitas vezes, confronta o modelo dominante (Brandenburg, 2010).

Uma escolha por outros modos de vida, dessa forma, pode ser uma ferramenta para a transformação social almejada, no momento em que a entende como uma forma de ressignificar a relação das pessoas com o território em que vivem e de repensar as relações sociais, de educação, de trabalho, de produção e de consumo. Essa identificação constitui ações que podem apoiar fortemente o enfrentamento ao modelo de desenvolvimento que desqualifica a defesa da vida humana no planeta. Essas propostas conjugam as premissas de cuidado e defesa da vida, produção de alimentos, consciência política e organizacional.

Portanto, abrange não só a transformação de todo o processo de produção de alimentos, mas uma reconfiguração das relações até então condicionadas pelo modelo hegemônico, que estrutura a ciência, a tecnologia e a sociedade de maneira geral, de forma a garantir a sua perpetuação. Caldart et al. $(2012$, p. 64) compreende que essa transformação é “[...] inseparável da luta pela soberania alimentar e energética, pela defesa da recuperação dos territórios, pelas reformas agrárias e urbanas, e pela cooperação e aliança entre os povos do campo e da cidade".

A convergência de individualidades em que o elo comum é a transformação dos modos de vida com o objetivo de uma vida melhor pode ser compreendida no pensamento de Freire (2000), quando considera que: 
[...] se, na verdade, não estou no mundo para simplesmente a ele me adaptar, mas para transformá-lo; se não é possível mudá-lo sem um certo sonho ou projeto de mundo, devo usar toda possibilidade que tenha para não apenas falar de minha utopia, mas participar de práticas com ela coerentes (FREIRE, 2000, p. 33).

Novas articulações individuais, relações diversas e novos grupos sociais são assim constituídos, frutos de uma inconformidade com o sistema convencional de produzir alimentos e da conscientização de seus danos ao planeta e à humanidade (ALIER, 2007). Sua organização é feita por cooperativas, movimentos sociais, instituições de educação e desenvolvimento, de forma independente do Estado (SINGER, 2002). Essa independência não é natural, mas se faz necessária pelo reconhecimento de que, a fim de atender às exigências do mercado agrícola convencional, regras de proteção ao meio ambiente e políticas de caráter social são flexibilizadas, afrouxadas e morosas, assim como a fiscalização sobre o cumprimento de leis, muitas das quais já obsoletas. Segundo Acselrad (2013 p. 64) "[...] as reformas liberais favoreceram concretamente, para os interesses das grandes corporações, ganhos de mobilidade que têm sido decisivos para a prosperidade capitalista em sua etapa flexível". Com isso, segundo o mesmo autor, "[...] as grandes corporações puderam assim escolher com maior liberdade as condições político-institucionais que lhes parecessem mais favoráveis para definir sua implantação espacial". Por essa razão, a essas empresas foi dado o poder de personalizar a configuração das políticas urbanas, ambientais e sociais a seu favor.

Convém salientar, no entanto, que não se trata de abandonar a responsabilidade do Estado sobre manutenção e criação de políticas ambientais e sociais, mas de um movimento de reação capaz de atender a urgência por medidas que revertam os danos causados pelo sistema capitalista neoliberal, principalmente sobre as populações mais vulneráveis. Devido aos ataques aos sistemas públicos feitos por esse sistema, iniciativas populares vieram para proporcionar propostas de autonomia rural e urbana, para diminuir os riscos da população a novas ou outras catástrofes e na busca universal de uma vida digna em tempo suficiente. Trata-se de uma reação ao modelo fixado pelo convencional, que tem no seu cerne interesses econômicos e financeiros, já que quanto mais lucram com as dinâmicas atuais, mais dificultam qualquer chance de transformação (SINGER, 2002).

Assim, o modo alternativo de vida na busca do bem viver constitui-se voltado a práticas de mudanças culturais que podem dialogar com os demais temas: ecológicos, sociais, políticos, institucionais e éticos, comprometidas com a melhoria das condições existenciais da humanidade e das demais espécies que compartilham ou virão a compartilhar o planeta. 
É fruto da relação dialógica entre as duas vertentes que compõem o ser humano: a biofísica e a psicossociocultural, de forma indissociável, valorizando as interações e retroações entre partes e todo, conforme Morin (2004).

É uma rede de dimensões que compõem a sustentabilidade das sociedades, já que envolvequestões como usos racionais da terrae dos demais recursosnaturais, educação, saberes, solidariedade, representação e participação política, economia, cultura e espiritualidade; posicionamento frente às mudanças socioambientais locais e globais (JOLLIVET, 1998).

As escolhas por alternativas de bem viver, enquanto originadas por uma reflexão das consequências ambientais e do modelo econômico tiveram seu despertar e foram consolidadas, principalmente, a partir dos questionamentos provocados pelos danos causados pela Revolução Verde, portanto são movimentos novos. No momento em que essa reflexão ocorre no sentido de buscar outros modos de vida que não reforcem nem contribuam na perpetuação do modelo de exploração da natureza e dos seres humanos, isso estabelece uma tensão entre o modelo histórico e a necessidade de uma outra proposta de modelo. Trata-se de uma reação ao modelo fixado pelo convencional, que tem no seu cerne interesses econômicos e financeiros, já que quanto mais lucram com as dinâmicas atuais, mais dificultam qualquer chance de transformação (BRANDENBURG, 2010).

Assim, se formos considerar que as sociedades contemporâneas foram, até então, desenvolvidas nesse modelo, a transição para outros modos de vida ainda é um processo desafiador. Desafiar as estruturas históricas que foram moldadas até então, nos campos como o educativo, por exemplo, e as contextuais e geradoras, como o estilo de vida, em que a percepção individual ou do grupo, a sua forma de pensar e a sua conduta são constituídas segundo as estruturas do que é perceptível, pensável e julgado razoável na perspectiva, no caso, do modelo hegemônico (BOURDIEU, 1996). Isso, portanto, reflete da interação das categorias que pré-constroem o mundo social, como as culturas de família, as educativas e as de trabalho, que até então, pela emergência desse outro movimento, sofreram a moldagem pelo sistema hegemônico a fim de repetir as condições favoráveis a essa dinâmica.

Segundo Leff (2001), uma quebra na repetição do sistema agroalimentar convencional requer mudanças importantes e estáveis das sociedades integradas à economia de mercado, na intenção de maior direção a redes alimentares alternativas que aproxima, geograficamente e socialmente, produtores e consumidores, com o objetivo de garantir alimentos saudáveis e acessíveis para todas as pessoas. Como efeito, a riqueza cultural, as relações de mercado, os interesses reais dos diferentes grupos sociais, 
comunidades tradicionais e as oportunidades de trabalho podem ser criadas e mantidas dentro das economias locais, contrariando todo o processo de dominação e subordinação historicamente construído na sociedade.

Assim, a percepção da crise de sustentabilidade, enquanto causada pelo modelo hegemônico, começa dentro do campo desse próprio modelo. Atua por uma reflexão, dentro dos próprios limites, sobre as restrições inculcadas e até então aceitas que apenas reforçaram e fomentaram esse modelo. Sendo assim, o próprio questionamento de condutas, relacionado com a necessidade de mudança a fim de transformar valores e práticas que até então conformam a estrutura estruturante do habitus ${ }^{7}$ que causou a crise, provoca uma conscientização (BOURDIEU, 1996).

Portanto, o posicionamento diante das regras dominantes nos campos em que se insere permite reflexões no momento em que as questiona. Uma ressignificação através de uma conscientização sobre meio ambiente e relações sociais pode conferir a esse campo um conflito entre os agentes que o dominam e os demais, isto é, entre os agentes que monopolizam os capitais específico do campo, que é exercida pela via da violência simbólica ${ }^{8}$ contra os agentes com pretensão à dominação (BOURDIEU, 1979). E, provocado por essa conscientização, a busca por alternativas resulta em um novo habitus, dessa vez com outro enfoque, o que dará a base para sua estrutura. Em outras palavras, é proposto um outro estilo de vida que não está totalmente dentro das regras dominantes e nem é determinado pela busca ao cumprimento dessas regras. Transpassa a linha única determinada entre posse e busca pela posse: é alternativo.

E é essa base, no momento em que é externalizada e partilhada no coletivo, que causa pontos de identificação que constitui a convergência e a comunhão entre os novos habitus na construção de estilos de vida alternativos. Verifica-se, portanto, que as disposições adquiridas pela experiência vivida pelos agentes sociais, indivíduos ou grupos, incorporam esse habitus gerador (BOURDIEU, 1996).

Após o estudo de como se constroem e se relacionam as dimensões da sustentabilidade do sistema agroalimentar, é possível compreender o quanto é complexo construir, realizar e executar formas de produção e consumo de alimentos e de relações

\footnotetext{
7 Para Bourdieu (1996) o habitus é um sistema de disposições, modos de perceber, de sentir, de fazer, de pensar, que nos levam a agir de determinada forma em uma circunstância dada.

8 Violência Simbólica é o resultado de um conjunto complexo de ações infraconscientes, de cada um dos agentes e cada uma das instituições dominantes sobre todos os demais, necessária para todo campo se reproduzir (BOURDIEU, 1996).
} 
sociais que não correspondam ao sistema hegemônico. Essa construção encontra muitos obstáculos, seja pelas diversas formas de resistência, pela escassez na provisão de condições favoráveis e pelas dificuldades impostas a fim de assegurar a continuidade do domínio absoluto do modelo capitalista.

Mas, mesmo que pareça não mais possível conciliar a produção de alimentos com a sustentabilidade, visto os valores atuais incorporados pelo modelo hegemônico de acumulação de capital financeiro, existem outras formas de produzir e de viver a fim de reverter esse quadro, demonstrando, na prática, como podem ser retomadas as articulações equilibradas entre as dimensões social, ecológica, econômica, política, cultural e ética a fim de uma sociedade mais justa e de respeito à natureza. Assim, o modo de bem viver tem a sua identidade como chave para uma transformação social, no momento em que a entende como uma forma de ressignificar a relação das pessoas com o território em que vivem e de repensar as relações sociais, de educação, de trabalho, de produção e de consumo.

Essa identificação constitui ações que podem apoiar fortemente o enfrentamento ao modelo de desenvolvimento que desqualifica a defesa da vida humana e das condições de vida no planeta. Nesta concepção, essas propostas conjugam as premissas de cuidado e defesa da vida, produção de alimentos, consciência política e organizacional.

Segundo Silva, Nascimento e Amaral (2020), a devastação do meio ambiente produz um desequilíbrio que favorece a aparição de doenças até então desconhecidas, como é o caso da Covid-19. Entendamos a seguir como isso acontece.

O Brasil é um país que exemplifica a articulação da vulnerabilidade social à vulnerabilidade ambiental na intensidade da Covid-19. No país, onde $25 \%$ da população vive abaixo da linha da pobreza e 13,5\% vive em situação de pobreza extrema (IBGE, 2019), ao mesmo tempo em que os índices de contaminação e mortes por Coronavírus cresceram exponencialmente, é possível observar a vulnerabilidade ambiental crescendo a passos largos. Visto o peso das práticas de gestão nos últimos anos e sua contribuição para a vulnerabilidade ambiental, essa determinante permite sua associação como causa e/ou agravante dessa e de outras epidemias.

Ainda que preliminarmente, entende-se que a crise mundial causada pela Covid-19 é mais um fator a apontar uma insustentabilidade, relacionada ao modelo hegemônico de produção e consumo de alimentos, construído à base de exclusão social, danos ambientais, má distribuição de terras e de renda, descompromisso político e falta de preocupação com o futuro do planeta (MORIN, 2020; SILVA; NASCIMENTO; AMARAL, 2020). Essa 
insustentabilidade indica um sistema frágil e instável, consequentemente diminuindo o seu potencial de resistência a catástrofes, cujo impacto pode ser tão repentino e potente que afeta o mundo inteiro e tem consequências mais pesarosas para populações em situações de vulnerabilidade (SILVA; NASCIMENTO; AMARAL, 2020). Portanto, a fim de reparar esse quadro e prevenir novas catástrofes, é urgente viabilizar, inserir e fomentar alternativas ao modelo convencional. São outros modelos, que se desenvolvem na direção de um sistema de produção e consumo que seja, ao mesmo tempo e na mesma importância, ambientalmente equilibrado, socialmente justo, economicamente viável e politicamente ético (ONU, 2020). Em outras palavras, se não se alterar a forma expropriadora com que o capitalismo lida com a natureza, ela lhe devolverá novas pandemias.

A pandemia de Covid-19, ao mesmo tempo em que expõe as fragilidades social e ecológica provocadas pelo sistema agroalimentar capitalista, permite que se fortaleça a pauta a favor de uma transformação urgente desse sistema (ONU, 2020). A reação ante a crise de sustentabilidade no modelo dominante de produção de alimentos gera a necessidade de uma reinvenção nos meios de produção e de consumo. Da mesma forma, tem ressaltado a importância da coletividade, no momento em que liga comportamentos individuais, como lavar as mãos e evitar sair de casa, como atitudes individuais que podem proteger a si e aos demais em seu entorno (AGAMBEN et al. 2020). Essa reinvenção envolve espaço para o questionamento da racionalidade econômica e tecnológica dominante e exige transformações nas sociedades.

As consequências dessa crise chamam as sociedades para a internalizar outros valores sobre bases de sustentabilidade ecológica e equidade social. Santos (2020) considera as crises expostas pela pandemia como oportunidade propícia a pensar, adotar e fortalecer alternativas ao modo de viver, de produzir, de consumir e de conviver, sem as quais não será possível evitar a irrupção de novas pandemias, inclusive mais letais. Sendo assim, novas abordagens, ou ressignificação das já existentes, contribuem para um processo de construção de modelos de vida que sejam alternativos ao modelo dominante, de forma a impedir ou minimizar o impacto causado pelas pandemias e mais desastres ambientais por sua continuidade (MORIN, 2020).

De acordo com Leff (2001), não se trata de parar de produzir ou de consumir, mas sim racionalizar a produção de alimentos de forma complexa, comprometida com a qualidade de vida de toda a sociedade, articulando todas as dimensões que envolvem a sustentabilidade, entendida como uma busca permanente de equilíbrio entre as relações 
dos diversos parâmetros que envolvem a produção e o consumo de alimentos. Portanto, fazem parte dessas práticas a possibilidade de vida saudável, uma lógica de respeito à natureza e um modelo de agricultura socialmente justo.

Esse outro modelo de sistema começa com uma agricultura que considera todos os seres vivos, através de ações compartilhadas entre o meio rural e o meio urbano, capaz de sustento digno das famílias rurais e fornecer à humanidade uma alimentação sustentável por meio de um consumo conscientizado. As ações podem se constituir pela racionalidade deste consumo, dando preferência a produtos menos industrializados, de produção local (que além de fortalecer a agropecuária tradicional ainda evitam o gasto de combustíveis no deslocamento dos produtos), de produtos de pequenas empresas familiares e/ou puramente nacionais, agroindústrias agroecológicas e feiras de produtores. Essas atitudes são exemplos que favorecem a independência de consumo vindo dos grandes conglomerados de exploração da natureza, propondo um outro estilo de vida a produtores e consumidores.

\section{Uma outra forma de viver é possível?}

O questionamento sobre a possibilidade de manter um outro mundo, através de diversas formas de adesão a um estilo de vida que deixe de corresponder ao sistema dominante, é constante e frequentemente posto à prova. Portanto, a fim de atingir esse objetivo, um complexo de várias ferramentas e ações são sempre chamados a serem criados, desenvolvidos e adaptados, a fim de manter essa alternativa estável e viável.

Em primeiro lugar, conforme visto no decorrer desse texto, as relações ambientais e alimentares não podem ser consideradas como puramente físicas: envolvem relações entre as pessoas (SILVA et. al, 2020). Portanto, as soluções a crises ocasionadas pelos problemas desses segmentos não podem ser somente técnicas e, sim, conjugar essas interações. Por essa razão, o aumento do crescimento e do interesse em perspectivas multi e interdisciplinares amplia o aprofundamento das relações entre seres humanos e meio ambiente.

É uma outra forma de ver o mundo e de pensar a sociedade, na medida em que se estabelece o contraponto entre a racionalidade ambiental (que propõe a reapropriação da natureza além do uso econômico) e a racionalidade instrumental capitalista. Na ideia de racionalidade ambiental, as várias dimensões do sistema e os vários saberes - populares e científicos - devem ser considerados na mesma proporção (CAPORAL; COSTABEBER, 2020). 
Para isso, a participação e representação dos sujeitos locais é elemento chave para definir os modelos de desenvolvimento locais, resistentes à dominação dos grandes conglomerados econômicos e à perpetuação da problemática já vista. Nesse sentido, são fundamentais os diálogos entre sabedoria e conhecimento, bem como a incorporação da educação como um dos instrumentos de conscientização e de organização.

Esses diálogos devem ser capazes de identificar as demandas e necessidades, a fim de suprir as carências de informação, construir caminhos de articulação entre sujeitos envolvidos, na busca de alternativas possíveis de transformação. Para isso, incentivo a projetos de educação e pesquisa em diversos níveis, alternativos à tendência a padronização, homogeneização e fragmentação da ciência, constitui um instrumento poderoso e abrangente a fim de formar referências de viabilidade e de exemplos que podem ser seguidos.

Em segundo lugar, na dimensão econômica, viabilizar o deslocamento da produção em grande escala para a produção de alimentos por agricultores familiares, rurais e urbanos, para assegurar a oferta local de alimentos frescos a preços justos, de forma independente das cadeias de mercado. Ao se consumir os produtos da agricultura familiar alternativa, é quebrado o ciclo de dominação das grandes empresas.

É possível, assim, uma promoção da valorização e do poder econômico dos produtores e dos pequenos comércios. Com essa valorização, aumentam as suas chances de permanecer em sua propriedade e com dignidade. Ao mesmo tempo, é possível proporcionar uma alimentação verdadeiramente nutritiva e livre de agrotóxicos, cada vez mais acessível a todos. A constante e crescente conscientização sobre a equidade na distribuição de terras para produção de alimentos saudáveis, a valorização das pessoas do campo, o acesso e permanência na terra, o crédito rural e a assistência técnica constituem as melhores bases para programas que visem o respeito ao meio ambiente, aos sujeitos do campo e a garantia de segurança alimentar e nutricional. Isso pode ser traduzido, em um sentido mais prático, em uma sistematização dos fatores necessários à criação de incentivos e linhas de financiamentos e demanda de legislação e regulamentos específicos (GRISA; NIEDERLE, 2020).

Em terceiro lugar, na dimensão da organização social e política, tais ações só podem ocorrer na medida em o Estado facilite a articulação de movimentos sociais, ambientalistas e de resistência, que reivindicam ações voltadas para a questão ambiental e para políticas públicas, assumindo o compromisso com uma transição do sistema de alimentação convencional como uma estratégia para uma ruptura das cadeias de abastecimento global (GRISA; NIEDERLE, 2020). 
Esses atores produzem uma contracultura alternativa à cultura da agricultura exploratória e do consumo exacerbado. Mesmo em escala local, colocam em xeque o modelo hegemônico de dominação. Seus movimentos, de reação à pressão e de resistência que buscam eliminar a hegemonia, constituem uma ecologia política, construída e fundamentada em uma ação transdisciplinar para dar conta da resistência e da mudança. São eles os atores capazes de iniciativas de reinvenção de projetos de vida a favor da agricultura e consumo sustentáveis.

É um movimento articulado e combinado de pessoas, que aderem a ela por sobrevivência ou por opção, a fim de contribuir com um mundo mais humano e sustentável de vários povos. É através desse movimento que vários grupos sociais, historicamente excluídos, recuperam a sua dignidade (BRANDENBURG, 2010). A eles se somam segmentos importantes de grupos urbanos, não excluídos socialmente, cuja busca é por uma outra forma de habitar no planeta, com maior sustentabilidade e maior qualidade nutricional e alimentar. Ou seja, (re)cria-se uma cadeia fora do modelo hegemônico da agricultura atual, articulando as diversas fases, desde a propriedade da terra, a produção de alimentos, a distribuição e troca dos produtos e o consumo.

\section{Considerações finais}

O modelo agropecuário convencional tem sido responsável por diversos desastres naturais, capaz, inclusive, de tornar mais drásticas as consequências de uma pandemia. No Brasil, os danos ambientais desse modelo se agravam, em diversas regiões do país, num cenário em que a estrutura de internações hospitalares, principalmente do setor público, já se encontrou em colapso ou próximo ao colapso devido à Covid-19.

Resultante do que vem sendo anunciado desde que se começou a estudar as consequências do modelo atual e hegemônico de agricultura sobre o meio ambiente, uma crise de grandes proporções já era prevista. Esse modelo tornou-se insustentável, a ponto de ser regido pela morte e não pela vida. Diante dessa questão-limite (entre a vida e o lucro), o convite é para a adoção ou conservação de práticas a favor da vida, para que possam chegar ao alcance de todas as sociedades.

Visto a ser uma proposta democrática, sua adesão pode ocorrer desde formas menos pretensiosa, como separar o lixo para reciclagem, até mais comprometida, como as comunidades alternativas agroecológicas que vem se desenvolvendo no Brasil desde a década de 1970. O importante é a mudança que provém da conscientização de que um estilo de vida compatível com o respeito a ela (à vida), em todas as suas formas, é real e possível. 


\section{Referências}

ACSELRAD, H. Liberalização da economia e flexibilização das leis - O meio ambiente entre o mercado e a justiça. Revista de Educação, Ciências e Matemática, v. 3, n. 3, set./dez. 2013.

AGAMBEN, G. et al. Sopa de Wuhan: pensamiento contemporáneo en tiempos de pandemias. Buenos Aires: Aspo, 2020. Disponível em: http://tiempodecrisis.org/wp-content/uploads/2020/03/Sopa-de-Wuhan-ASPO. pdf?fbclid=IwAR386959-_q7FG9ZCeGsEFSxGBOerZNNMf3s1 hmLn8nYjcieT4QA-yyx6zE. Acesso em: 28 jun. 2020.

ALIER, J. M. Ecologismo dos pobres: conflitos ambientais e linguagens de valoração. São Paulo: Contexto, 2007.

ANDRADE, D. C; ROMEIRO, A. R. Degradação ambiental e teoria econômica: algumas reflexões sobre uma "Economia dos ecossistemas". EconomiA, Brasília, v. 12, n. 1, p. 3-26, jan./abr. 2011. Disponível em: https:// anpec.org.br/revista/vol12/vol12n1p3_26.pdf. Acesso em: 16 jul. 2021.

AUGUSTO, L. G. S. et al. Dossiê Abrasco - Um alerta sobre os impactos dos agrotóxicos na saúde. Parte 2 Agrotóxicos, Saúde, Ambiente e Sustentabilidade. Rio de Janeiro: Abrasco, 2012. Disponível em: https://www. abrasco.org.br/site/wp-content/uploads/2015/03/Dossie_Abrasco_02.pdf. Acesso em: 16 jul. 2021.

BARUTTI, S. Mal comidos. Buenos Aires: Planeta, 2013.

BORSATTO, R. S. A Agroecologia e sua apropriação pelo Movimento dos Trabalhadores Rurais Sem Terra (MST) e assentados da reforma agrária. 2011. 298 f. Tese (Doutorado em Engenharia Rural) - Faculdade de Engenharia Agrícola, Universidade Estadual de Campinas, Campinas, 2011.

BOSQUEROLLI, A. M. et al. Brasil e o mundo diante da Covid-19 e da crise econômica. Disponível em: https:// www.ufpr.br/portalufpr/wp-content/uploads/2020/07/Brasil-e-o-mundo-diante-da-Covid-19-e-da-criseeconomica.pdf. Curitiba: PET Economia/UFPR, 2020. Acesso em: 16 jul. 2021.

BOURDIEU, P. A distinção: crítica social do julgamento. São Paulo: Edusp; Porto Alegre: Zouk, 1979.

BOURDIEU, P. Razões práticas: sobre a teoria da ação. Campinas: Papirus, 1996.

BRANDENBURG, A. Do rural tradicional ao rural socioambiental. Ambiente e Sociedade, v. 13, n. 12, p. 417-428, jul./dez. 2010. Disponível em: https://www.scielo.br/pdf/asoc/v13n2/v13n2a13.pdf. Acesso em: 26 de jun. 2020.

CALDART, R. S.; PEREIRA, I. B.; ALENTEJANO, P.; FRIGOTTO, G. Dicionário da Educação do Campo. 2. ed. São Paulo: Expressão Popular, 2012.

CAPORAL, J. A.; COSTABEBER, F. R. Análise funcional da sustentabilidade. Revista Agroecologia e Desenvolvimento Rural Sustentável, Porto Alegre, v. 3, n. 3, p. 70-85, jul./set. 2002.

ELIAS, N. A Sociedade dos Indivíduos. Rio de Janeiro: Jorge Zahar, 1994.

FREIRE, P. Cartas pedagógicas e outros escritos. São Paulo: UNESP, 2000.

FOOD AND AGRICULTURE ORGANIZATION OF THE UNITED NATIONS (FAO); INTERNATIONAL FUND FOR AGRICULTURAL DEVELOPMENT (IFAD); UNITED NATIONS CHILDREN'S FUND (UNICEF); WORLD FOOD PROGRAMME (WFP); WORLD HEALTH ORGANIZATION (WHO). The state of food security and nutrition in the world 2018. Building climate resilience for food security and nutrition. Rome: FAO, 2018.

GRISA, C.; NIEDERLE, P. É urgente inovar nas políticas alimentares fortalecendo a agricultura familiar. Sul21, maio 2020. Disponível em: https://sul21.com.br/opiniao/2020/05/e-urgente-inovar-nas-politicas-alimentaresfortalecendo-a-agricultura-familiar-por-catia-grisa-e-paulo-niederle/. Acesso em: 19 jul. 2021.

HARVEY, D. O novo imperialismo. 2. ed. São Paulo: Loyola, 2005. 
HARVEY, D. Política anticapitalista en tiempos de coronavírus. In: AGAMBEN, G. et al. Sopa de Wuhan: pensamiento contemporáneo en tiempos de pandemias. Buenos Aires: Aspo, 2020. p. 79-96. Disponível em: https://www3. unicentro.br/defil/wp-content/uploads/sites/67/2020/05/Sopa-de-Wuhan-ASPO.pdf. Acesso em: 28 jun. 2020.

INSTITUTO BRASILEIRO DE GEOGRAFIA E ESTATÍSTICA (IBGE). Censo agropecuário 2017. IBGE (2018). Disponível em: https://censos.ibge.gov.br/agro/2017/templates/censo_agro/resultadosagro/index.html. Acesso em: 7 jun. 2020.

INSTITUTO BRASILEIRO DE GEOGRAFIA E ESTATÍSTICA (IBGE). Coordenação de População e Indicadores Sociais. Síntese de indicadores sociais: uma análise das condições de vida da população brasileira: 2019. Rio de Janeiro: IBGE, 2019. Disponível em: https://biblioteca.ibge.gov.br/visualizacao/livros/liv101678.pdf. Acesso em: 14 maio 2020.

INSTITUTO NACIONAL DE PESQUISAS ESPACIAIS (INPE). Programa Queimadas. Relatórios e Publicações. Disponível em: http://queimadas.dgi.inpe.br/queimadas/portal-static/situacao-atual/. Acesso em: 14 maio 2020.

JOLLIVET, M. A "vocação atual" da Sociologia Rural. Estudos, Sociedade e Agricultura, n. 11, p. 5-25, out. 1998.

LEFF, E. Saber ambiental: sustentabilidade, racionalidade, complexidade, poder. Petrópolis: Vozes, 2001.

MADEIRA, F. B. et al. Estilos de vida, habitus e promoção da saúde: algumas aproximações. Saúde e Sociedade. São Paulo, v. 27, n. 1, p. 106-115, 2018. Disponível em: https://www.scielosp.org/pdf/sausoc/2018.v27n1/106115/pt. Acesso em: 28 jun. 2020.

MORAES, F. C. de et al. Movimento Educador "Ecossocialismo e Bem Viver". In: SORENTINO, M.; RAYMUNDO, M. E. A.; PORTUGAL, S.; MORAES, F. C.; SILVA, R. F. (Orgs.). Educação, Agroecologia e bem viver: transição ambientalista para sociedades sustentáveis. Piracicaba: MH-Ambiente Natural, 2017.

MORIN, E. Os sete saberes necessários à educação do futuro. São Paulo: Cortez, 2001.

MORIN, E. A cabeça bem-feita: repensar a reforma, reformar o pensamento. 10. ed. Rio de Janeiro: Bertrand Brasil, 2004.

MORIN, E. É hora de mudarmos de via: as lições do coronavírus. Rio de Janeiro: Bertrand Brasil, 2020.

OBREGÓN, A. Q."Bem viver": entre o "desenvolvimento"e a "des/colonialidade" do poder. Revista da Faculdade de Direito da UFG, v. 37, n. 1, p. 46-57, 2013.

OCTAVIANO, C. Muito além da tecnologia: os impactos da Revolução Verde. ComCiência, n. 120, 2010. Disponível em: http://comciencia.scielo.br/pdf/cci/n120/a06n120.pdf. Acesso em: 16 jul. 2021.

ORGANIZAÇÃO DAS NAÇÕES UNIDAS (ONU). Programa das Nações Unidas para o Meio Ambiente (Pnuma). 6 fatos sobre Coronavírus e meio ambiente. 2020. Disponível em: https://ciclovivo.com.br/covid19/6-fatossobre-coronavirus-e-meio-ambiente/. Acesso em: 19 jul. 2021.

PAZMIÑO, C. P. et al. Agriculturas alternativas en Latinoamérica. Tipología, alcances y viabilidad para la transformación social-ecológica. México: Fundación Friedrich Ebert, 2017. Disponível em: http://library.fes.de/ pdf-files/bueros/mexiko/13957.pdf. Acesso em: 15 maio 2020.

PIGNATI, W. A.; MACHADO, J. M. H. O agronegócio e seus impactos na saúde dos trabalhadores e da população do estado de Mato Grosso. In: GOMEZ, C. M., MACHADO, J. M. H.; PENA, P. G. L. (Comps.). Saúde do trabalhador na sociedade brasileira contemporânea. Rio de Janeiro: Fiocruz, 2011. p. 245-272. Disponível em: http:// books.scielo.org/id/qq8zp/pdf/minayo-9788575413654-13.pdf. Acesso em: 16 jul. 2021.

PLOEG, J. D. van der. O modo de produção camponês revisitado. In: SCHNEIDER, Sérgio (Org.). A diversidade da agricultura familiar. Porto Alegre: UFRGS, 2006. p. 13-54. 
PLOEG, J. D. van der. Camponeses e impérios alimentares: lutas por autonomia e sustentabilidade na era da globalização. Porto Alegre: UFRGS, 2008.

PORTO, M. F; SOARES, W. L. Modelo de desenvolvimento, agrotóxicos e saúde: um panorama da realidade agrícola brasileira e propostas para uma agenda de pesquisa inovadora. Revista Brasileira de Saúde Ocupacional, São Paulo. v. 37, n. 125. p. 17-31, 2012.

RIBEIRO, H; ASSUNÇÃO, J. V. de. Efeitos das queimadas na saúde humana. Estudos Avançados, v. 16, n. 44, abr. 2002. Disponível em: https://www.scielo.br/j/ea/a/5KxLnbYV6c8kRph4Dxd49rv/?lang=pt Acesso em: 19 jul. 2021.

SANTOS, Boaventura de Sousa. 2020. A cruel pedagogia do vírus (Pandemia Capital). São Paulo: Boitempo, 2020.

SCHNEIDER, S. et al. Os efeitos da pandemia da Covid-19 sobre o agronegócio e a alimentação.

Estudos Avançados, v. 34, n. 100, set./dez. 2020. Disponível em: https://www.scielo.br/j/ea/a/ kQdC7V3FxM8WXzvmY5rR3SP/?format=pdf\&lang=pt. Acesso em: 16 jul. 2021.

SCHNEIDER, C.; OLIVEIRA, M. S. Saúde única e a Pandemia de Covid-19. In: BUSS, P. M.; FONSECA, L. E. (Eds.). Diplomacia da saúde e Covid-19: reflexões a meio caminho. Rio de Janeiro: Observatório Covid 19: Fiocruz, 2020. p. 83-96. Disponível em: http://books.scielo.org/id/hdyfg/pdf/buss-9786557080290-08.pdf. Acesso em: 16 jul. 2021.

SILVA, D. S. da C.; SANTOS, M. B. dos; SOARES, M. J. N. Impactos causados pela COVID-19: um estudo preliminar. Revista Brasileira de Educação Ambiental (RevBEA), v. 15, n. 4, p.128-147, 2020a. Disponível em: https:// periodicos.unifesp.br/index.php/revbea/article/view/10722. Acesso em: 16 jul. 2021.

SILVA, M. R. de O.; NASCIMENTO, R. C. do; AMARAL, A. R. P. Impactos socioambientais e a pandemia do novo Coronavírus. Holos, v. 36, n. 5, p. 1-13, 2020.

SINGER, P. Introdução à Economia Solidária. São Paulo: Fundação Perseu Abramo, 2002. 